\title{
Prevalência de tuberculose bovina em animais e rebanhos abatidos em 2009 no estado de Mato Grosso, Brasil
}

\author{
[Prevalence of bovine tuberculosis in herds and animals slaughtered in 2009 in the \\ State of Mato Grosso, Brazil] \\ L.V. Furlanetto ${ }^{1}$, E.E.S. Figueiredo ${ }^{2 *}$, C.A. Conte Júnior ${ }^{1}$, F.G.S. Silva ${ }^{3}$, R.S. Duarte ${ }^{1}$, \\ J.T. Silva ${ }^{1}$, W. Lilenbaum ${ }^{4}$, V.M.F. Paschoalin ${ }^{1}$ \\ ${ }^{1}$ Universidade Federal do Rio de Janeiro - Rio de Janeiro, RJ \\ ${ }^{2}$ Universidade Federal de Mato Grosso - Cuiabá, MT \\ ${ }^{3}$ Universidade de Cuiabá - Cuiabá, MT \\ ${ }^{4}$ Universidade Federal Fluminense - Niterói, RJ \\ RESUMO
}

\begin{abstract}
Estimou-se a prevalência de tuberculose em bovinos, e em seus respectivos rebanhos, abatidos em 2009 no estado de Mato Grosso, utilizando como diagnóstico confirmatório o exame bacteriológico e o molecular a partir de fragmentos de tecidos lesionados. Nos sete abatedouros selecionados, detentores de serviço de inspeção federal (SIF), foram inspecionados 41.193 bovinos, sadios ao exame ante mortem, procedentes de 492 rebanhos originários de 85 (60\%) municípios mato-grossenses. Um total de 198 carcaças apresentaram lesões suspeitas. Apenas três carcaças (3/198) apresentaram lesões confirmadas como tuberculosas pelos diagnósticos laboratoriais. A prevalência aparente de tuberculose bovina em animais e rebanhos abatidos no estado de Mato Grosso foi de $0,007 \%$ [IC 95\% $=-0,001 \% ; 0,016 \%$ ] e $0,61 \%$ [IC 95\% $=-0,08 \% ; 1,30 \%$ ], respectivamente. O estado do Mato Grosso possui, naturalmente, um status sanitário considerado de baixa prevalência.
\end{abstract}

Palavras-chave: tuberculose bovina, prevalência, abatedouro, PCR múltipla

\begin{abstract}
The prevalence of bovine tuberculosis in cattle, and its herds, slaughtered in 2009 in the state of Mato Grosso, Brazil, was estimated using bacteriological analysis and molecular test, from fragments of injured tissues as well as direct DNA templates. 41,193 cattle, which appeared healthy in the ante mortem examination, from seven selected slaughterhouses, under Brazilian federal inspection services (SIF), were inspected. The animals were from 492 herds located in 85 (60\%) different cities of Mato Grosso. A total of the 198 carcasses had suspicious lesions. Three carcasses (3/198) had lesions that were found to be tuberculous in laboratory diagnosis. The apparent prevalence of bovine tuberculosis in the total number of animals and in herds slaughtered in Mato Grosso was 0.007\% [IC 95\% = -0.001\%;0.016\%] and $0.61 \%$ [IC 95\% = -0.08\%; $1.30 \%]$, respectively. The sanitation status demonstrated in Mato Grosso indicates the progress in this state toward the eradication of bovine tuberculosis.
\end{abstract}

Keywords: bovine tuberculosis, prevalence, slaughterhouse, multiplex PCR

\section{INTRODUÇÃO}

A tuberculose bovina (TB), uma zoonose causada pelo Mycobacterium bovis, apresenta sérios riscos tanto à saúde pública humana

Recebido em 10 de setembro de 2011

Aceito em 28 de novembro de 2011

*Autor para correspondência (corresponding author)

E-mail:figueiredoeduardo@ufmt.br quanto à veterinária, em especial em indivíduos convalescentes ou imunodebilitados, pela susceptibilidade do homem ao bacilo, além de ocasionar impactos à produtividade dos rebanhos e expressivas perdas econômicas ao setor. $\mathrm{Na}$ tentativa de reduzir a prevalência e a incidência 
de novos focos da doença no Brasil, país que detém o maior rebanho comercial do mundo, com mais de 205 milhões de bovinos, foi instituído, em 2004, o Programa Nacional de Controle e Erradicação da Brucelose e Tuberculose Animal (PNCEBT), baseado no método de "teste-e-abate" e que conta com a colaboração dos serviços de inspeção oficiais no que diz respeito à vigilância da tuberculose nos abatedouros (Brasil, 2004; Instituto..., 2010).

Esta importante zoonose tem distribuição mundial, e sua prevalência ainda é marcante nos países em desenvolvimento. No Brasil não existem dados oficiais atualizados quanto à prevalência de $\mathrm{TB}$, sendo que, na última estimativa - realizada com informações de 1989 a 1998 -, a média nacional foi de 1,3\% de animais infectados (Brasil, 2004). Em um levantamento mais recente, a estimativa da prevalência de animais doentes no Brasil foi de $0,83 \%$, sendo que a região Centro-Oeste apresentou a menor prevalência dentre as regiões brasileiras, com 0,37\% (Roxo, 2004; Kantor e Ritacco, 2006). A distribuição geográfica de TB pode apresentar variações de acordo com os sistemas de criação e práticas sanitárias e tecnológicas desempenhadas em cada região, principalmente em países continentais e detentores de vários biomas, como o Brasil.

A bovinocultura é uma das principais atividades da economia do estado de Mato Grosso, o qual apresenta o maior rebanho bovino brasileiro, com cerca de 28 milhões de cabeças, distribuídas em mais de 107 mil propriedades, designadas no presente trabalho como rebanhos (Instituto..., 2011). Em um estudo prévio realizado em abatedouros sob inspeção oficial, neste mesmo estado, foi relatado que apenas $0,05 \%$ (27/57.641) das carcaças foram condenadas por apresentarem lesões sugestivas de TB, entretanto a presença de $M$. bovis foi confirmada, pelo diagnóstico bacteriológico, em 14,8\% (4/27) dessas lesões (Salazar, 2005). Esperava-se que a prevalência estimada em achados de inspeção post mortem realmente fosse inferior aos obtidos pelo diagnóstico in vivo (Baptista et al., 2004), porém os dados obtidos a partir de abatedouros podem indicar o status sanitário da doença no rebanho.

A inspeção post mortem de rotina - exame anatomopatológico ou macroscópico - é crucial para o diagnóstico de TB em abatedouros. Porém, em razão de fortes semelhanças entre as lesões causadas pela tuberculose e outras, muitas vezes não é possível identificar todos os animais doentes (Corner, 1994; Reis et al., 1995). Diversos estudos vêm demonstrando a possibilidade do uso da PCR na detecção de $M$. bovis em fragmentos de lesões sugestivas de tuberculose, permitindo, assim, um aumento da acurácia e também significativa redução do tempo do diagnóstico padrão (Liebana et al., 1995; Wards et al., 1995; Zanini et al., 2001; Meickle et al., 2007; Cardoso et al., 2009).

O presente estudo teve por objetivo estimar a prevalência de tuberculose bovina em rebanhos e em animais do estado de Mato Grosso, a partir da inspeção post mortem em abatedouros sob serviço de inspeção federal (SIF), utilizando como diagnóstico confirmatório os exames bacteriológico e molecular (PCR) realizados diretamente em fragmentos dos tecidos lesionados.

\section{MATERIAL E MÉTODOS}

Foram acompanhados o abate e a inspeção post mortem de bovinos em sete abatedouros detentores de SIF, localizados em seis diferentes municípios do estado de Mato Grosso (Fig. 1A). Para que a amostragem fosse representativa quanto ao rebanho estadual, foram selecionados abatedouros situados em localidades com efetivo de rebanho bovino expressivo (Fig. 1B), em quatro mesorregiões do estado: sudeste, centrosul, sudoeste e norte. O período de coleta em cada abatedouro foi de aproximadamente 10 dias úteis e ocorreu em datas distintas, no período entre maio e outubro de 2009.

Não houve coleta de amostras na mesorregião nordeste pela indisponibilidade de estabelecimentos com SIF no período estudado, porém, os animais dessa região foram abatidos no município de Paranatinga, incluído no presente estudo. Os locais de coleta selecionados abrangeram os quatro circuitos mato-grossenses produtores de bovinos, divididos, conforme Negreiros et al. (2009), em: Pantanal representado neste estudo pelos municípios de Cáceres e Várzea Grande -; Leite Rondonópolis -; Engorda - Paranatinga -; e Cria - Juara e Tangará da Serra. Apenas no município 
de Juara foi acompanhado o abate em dois estabelecimentos.

Durante o estudo, foram coletados fragmentos e/ou tecidos a partir das lesões classificadas pelo SIF como sugestivas de TB ou linfadenites provenientes de partes do bovino frequentemente acometidas pela tuberculose, isto é, nos linfonodos da porção dianteira da carcaça - cabeça, cavidade torácica e região cervical da carcaça. Após identificadas, as lesões encontradas foram fotografadas, e diferentes amostras foram enviadas devidamente acondicionadas, sendo mantidas a $-20^{\circ} \mathrm{C}$ até a realização do exame bacteriológico e da PCR múltipla (m-PCR).

Informações sobre o escore corporal, sexo e idade do animal, e dados relacionados à origem município e propriedade -, e condição sanitária dos animais, como a participação ou não do PNCEBT (Brasil, 2004), foram obtidos durante as coletas e por meio da Guia de Trânsito Animal (GTA) do lote.

As amostras coletadas foram submetidas ao exame bacteriológico, método padrão de diagnóstico da tuberculose, após descontaminação com cloreto de hexadecilpiridínio (HPC) a $0,75 \%$ e Petroff adaptado $(\mathrm{NaOH} 4 \%)$ paralelamente e, em seguida, semeadas em tubos com meio de Stonebrink e Löwenstein-Jensen (Furlanetto, 2011). O DNA das colônias isoladas foi extraído por lise térmica a $100^{\circ} \mathrm{C}$ por 10 min e submetido a m-PCR conforme descrito por Figueiredo et al. (2009), para a identificação bacteriana.

Fragmentos de tecido das lesões também foram utilizados como moldes de DNA, diretamente nas reações de m-PCR, usando oligonucleotídeos para amplificação das sequências genômicas RvD1Rv2031c e IS6110, específicas para $M$. bovis e para o complexo Mycobacterium tuberculosis, respectivamente. A extração do DNA e as condições da m-PCR foram realizadas conforme descrito por Furlanetto (2011).

Para calcular o tamanho da amostra destinada a estimar a prevalência de bovinos acometidos pela tuberculose, abatidos no estado do Mato Grosso, foram considerados o grau de confiança de $95 \%$ e o nível de precisão absoluta dos resultados de $\pm 0,022 \%$ (Noordhuizen et al., 1997). A prevalência esperada utilizada no cálculo foi de $0,05 \%$, com base nos resultados obtidos por Salazar (2005).
Dessa maneira, foi calculado que seria necessário inspecionar 39.666 animais, de acordo com a fórmula padrão para amostragem aleatória simples, entretanto foi inspecionado um total de 41.193 animais. O tamanho da amostra para estimar a prevalência em rebanhos deu-se em consequência da origem dos animais avaliados, correspondendo a 492 rebanhos. O rebanho foi considerado positivo quando pelo menos um animal foi diagnosticado para TB nos exames laboratoriais.

Devido às características inerentes ao desenho do estudo - estimativa da prevalência de animais tuberculosos a partir da amostragem apenas de animais destinados ao abate e desconhecimento do efetivo de bovinos de cada propriedade amostrada -, não foi possível determinar o cálculo de prevalência real. Portanto, foi calculada a prevalência aparente simples $(\mathrm{Pa})$ de $\mathrm{TB}$ em rebanhos e animais abatidos em Mato Grosso, de acordo com o método descrito por Martin et al. (1987).

\section{RESULTADOS E DISCUSSÃO}

Do total de 41.193 bovinos avaliados, sadios ao exame ante mortem e sem restrições sanitárias conforme a GTA, $198(0,48 \%)$ apresentaram lesões sugestivas de TB ou linfadenites na porção dianteira da carcaça, durante o exame post mortem (Tab. 1). Pela avaliação do SIF, apenas uma carcaça apresentou lesão sugestiva de tuberculose, e as lesões das outras 197 foram julgadas como linfadenites comuns ou inespecíficas.

Adotou-se o critério de coletar não apenas as lesões consideradas sugestivas de tuberculose, mas todas aquelas que mostravam linfadenites provenientes dos linfonodos da cabeça, cavidade torácica e região cervical da carcaça. Dessa forma, seria evitada a perda de potenciais amostras positivas em decorrência de erros na interpretação da observação macroscópica das lesões, devido às semelhanças entre as lesões em linfonodos provocadas pela tuberculose, linfossarcoma ou linfadenites inespecíficas (Reis et al., 1995). A opção de avaliar todas as lesões localizadas nos linfonodos da porção dianteira da carcaça foi devido a estudos anteriores, que demonstraram que até $86 \%$ das lesões de tuberculose ocorrem nos linfonodos da cabeça e da cavidade torácica (Corner et al., 1990; Whipple et al., 1996; Asseged et al., 2004). 


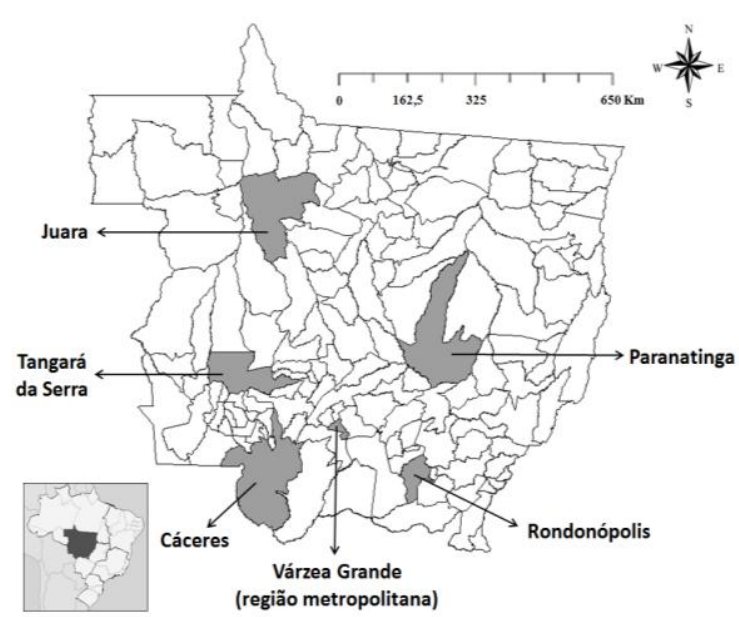

A

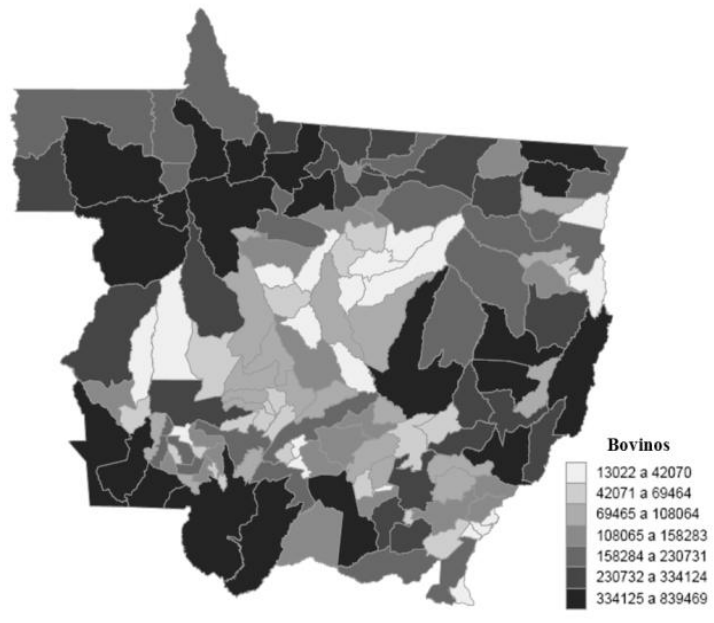

B

Figura 1. Mapas com ilustrações dos locais de coleta e efetivo bovino no estado de Mato Grosso, Brasil. (A) Municípios onde foram coletadas as amostras; (B) efetivo do rebanho bovino de Mato Grosso distribuído por municípios. Fonte: (Instituto..., 2007).

Tabela 1. Ocorrência de lesões sugestivas de tuberculose bovina em linfonodos da porção dianteira da carcaça, diagnosticadas durante a inspeção post mortem em bovinos em abatedouros no estado de Mato Grosso, entre maio e outubro de 2009

\begin{tabular}{lccc}
\multicolumn{1}{c}{ Município de coleta } & \multirow{2}{*}{ Bovinos abatidos } & \multicolumn{2}{c}{ Carcaças que apresentaram lesão } \\
\hline Cáceres & & $\mathrm{n}$ & $\%$ \\
Juara & 4.328 & 77 & 1,78 \\
Paranatinga & 6.591 & 17 & 0,26 \\
Rondonópolis & 8.068 & 23 & 0,29 \\
Tangará da Serra & 5.914 & 03 & 0,05 \\
Várzea Grande & 9.689 & 20 & 0,21 \\
Total & 6.603 & 58 & 0,80 \\
\hline
\end{tabular}

Os 41.193 animais inspecionados foram provenientes de 492 rebanhos situados em 85 (60\%) municípios do estado de Mato Grosso (Fig. 2). Dentre os bovinos abatidos, 76,2\% eram machos e $23,8 \%$ fêmeas; $2,4 \%$ tinham idade entre um e dois anos, $54,2 \%$ entre dois e três anos e 43,4\% mais de três anos. Os animais procedentes de rebanhos monitorados pelo PNCEBT corresponderam a $77,8 \%$ do total. Mesmo sendo abatidos animais procedentes de apenas seis municípios do nordeste matogrossense, estes representaram 6,1\% (2.533) dos bovinos avaliados.

Fez-se isolamento de micobactérias em três amostras, perfazendo $1,5 \%$ do total, que foram posteriormente identificadas como $M$. bovis, por ensaio de m-PCR. O mesmo resultado foi obtido quando a m-PCR foi realizada diretamente dos fragmentos de tecidos com lesões, ou seja, confirmando a presença do DNA de $M$. bovis nas mesmas três lesões das quais foram isoladas as bactérias. Não foi detectada a presença de $M$. bovis na lesão classificada como tuberculosa pelo SIF em uma das carcaças.

Considerando-se a cultura como método padrão de diagnóstico de tuberculose (Corner, 1994), foi demonstrado que a m-PCR teve sensibilidade e especificidade idênticas às da bacteriologia (100\%). Entretanto, a m-PCR é uma técnica rápida, podendo ser realizada em, no máximo, dois dias de trabalho, tempo muito menor que o necessário para conclusão pelas análises bacteriológicas. Aliando especificidade e rapidez, a técnica de $\mathrm{m}$-PCR poderia ser utilizada para auxiliar a vigilância de TB em abatedouros. 


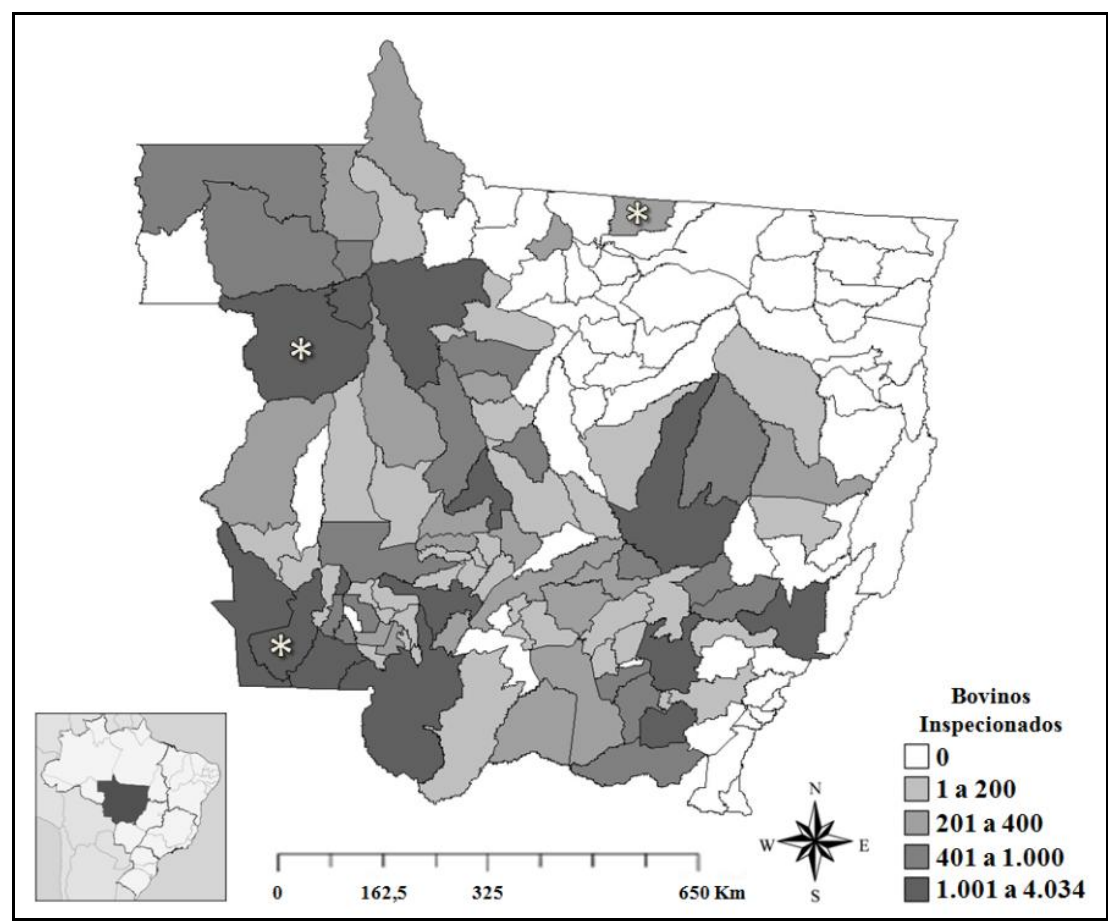

Figura 2. Municípios mato-grossenses de procedência dos bovinos abatidos e inspecionados durante o estudo - maio a outubro de 2009.

*Municípios de procedência dos três animais doentes.

As lesões das quais foram isolados M. bovis foram provenientes de linfonodos retrofaringeanos de carcaças de animais de três rebanhos, sendo estes procedentes dos municípios de Guarantã do Norte e Juína, situados na mesorregião norte, e de Pontes e Lacerda, no sudoeste do estado de Mato Grosso (Fig. 2). Os municípios estão localizados no circuito pecuário de Cria, segundo Negreiros et al. (2009).

Portanto, a prevalência aparente de TB em animais e rebanhos de Mato Grosso, a partir da vigilância post mortem em abatedouros com $\mathrm{SIF}$, foi de $0,007 \%$ [IC 95\% $=-0,001 \% ; 0,016 \%$ ] e $0,61 \%$ [IC $95 \%=-0,08 \% ; 1,30 \%$ ], respectivamente.

A estimativa da prevalência de tuberculose nos bovinos abatidos em Mato Grosso foi semelhante ao valor citado por Salazar (2005) por meio de análises bacteriológicas, o qual encontrou ocorrência de $0,007 \%(04 / 57.641)$ de casos confirmados de TB, provenientes de lesões em $27(0,05 \%$ de 57.641$)$ carcaças condenadas por apresentarem lesões sugestivas de tuberculose em estabelecimentos com serviço de inspeção sanitária estadual (SISE) de Mato Grosso. Este estudo foi realizado entre novembro de 2004 e agosto de 2005, período da implantação do PNCEBT (Brasil, 2004).

A obtenção de resultado semelhante pelo presente estudo, quatro anos após o início do PNCEBT, indica a lenta evolução do programa no estado e a necessidade de um maior comprometimento de todos os elos, públicos e privados, envolvidos neste processo.

No período entre 1993 e 1997, a prevalência de tuberculose em bovinos abatidos em dez estabelecimentos com SIF no estado de Minas Gerais foi de $0,08 \%$, considerando-se os achados macroscópicos oficiais (Baptista et al., 2004). Já a estimativa da prevalência aparente de animais infectados no mesmo estado, utilizando-se o exame in vivo da tuberculinização comparada, foi 10 vezes mais alta, $0,8 \%$, conforme levantamento realizado em 1999, envolvendo 1.586 propriedades e 22.990 animais (Belchior, 2000). Portanto, seria esperado que a prevalência estimada, baseada em dados obtidos de inspeção post mortem, fosse inferior à obtida pelo diagnóstico in vivo. 
Com base neste raciocínio, a expectativa é de que a prevalência de TB no rebanho bovino no estado de Mato Grosso seja maior que a estimada pelo presente estudo, pois a inspeção de rotina nos abatedouros pode não identificar todos os animais doentes (Corner, 1994). Outros eventos extrínsecos à inspeção também podem interferir amplamente na estimativa, como os grupos de abate não constituírem amostras aleatórias, a possível canalização dos animais de descarte para os abatedouros estaduais, municipais ou estabelecimentos clandestinos e, ainda, a eliminação dos bovinos positivos na própria unidade de criação. Contudo, a baixa prevalência encontrada nos abatedouros pode ser um indicativo da realidade sanitária da doença no rebanho mato-grossense.

Áreas consideradas de baixa prevalência ou virtualmente livres de tuberculose são aquelas que apresentam estimativas inferiores a $0,1 \%$ (Kantor e Ritacco, 2006). Portanto, o resultado obtido poderia estar subestimando em até 14 vezes o total de animais infectados, e, ainda assim, o estado de Mato Grosso permaneceria nessa categoria. O levantamento da doença nas fazendas, em amostras representativas, poderia proporcionar estimativa confirmatória (Baptista et al., 2004).

O status de baixa prevalência encontrada no estado já era esperado, uma vez que Mato Grosso apresenta clima tropical, possui um sistema de criação de bovinos predominantemente extensivo, voltado à pecuária de corte, há o abate precoce dos animais e baixa lotação das pastagens, com média estadual estimada em até uma unidade animal (UA)/ha (Furlanetto et al., 2010). Portanto, os animais têm menos contato entre si e menor tempo de exposição a possíveis membros infectados do rebanho (Abrahão, 1999).

Em regiões como Mato Grosso, onde a prevalência da doença é naturalmente muito baixa, a implantação de eficientes sistemas de vigilância, integrando os serviços de inspeção oficiais com o de defesa sanitária, pode ser de grande valia na detecção de focos remanescentes. O diagnóstico molecular associado à inspeção post mortem em abatedouros seria uma estratégia eficiente para acelerar o processo de erradicação de tuberculose no rebanho bovino dessas regiões.

\section{CONCLUSÕES}

A prevalência aparente de tuberculose em bovinos e rebanhos abatidos em estabelecimentos sob SIF no estado de Mato Grosso foi de $0,007 \%$ [IC $95 \%=-0,001 \%$; $0,016 \%$ ] e $0,61 \%$ [IC $95 \%=-0,08 \% ; 1,30 \%$ ], respectivamente. Os resultados demonstram que o estado de Mato Grosso apresenta, naturalmente, um status sanitário considerado de baixa prevalência, que o credencia a avançar para a etapa de erradicação da tuberculose bovina. A associação entre a inspeção post mortem de rotina e o diagnóstico molecular (m-PCR) a partir de fragmentos de tecidos lesionados parece ser uma estratégia adequada para acelerar este processo.

\section{AGRADECIMENTOS}

À FAPERJ, à FAPEMAT e ao CNPq, pelo suporte financeiro, e à Superintendência Federal de Agricultura de Mato Grosso (SFAMT/MAPA), pela colaboração na obtenção de informações e amostras nos abatedouros.

\section{REFERÊNCIAS}

ABRAHÃO, R.M.C.M. Tuberculose humana causada pelo Mycobacterium bovis: considerações gerais e a importância dos reservatórios animais. Arch. Vet. Sci., v.4, p.5-15, 1999.

ASSEGED, B.; WOLDESENBET, Z.; YIMER, E.; LEMMA, E. Evaluation of abattoir inspection for the diagnosis of Mycobacterium bovis infection in cattle at Addis Adaba abattoir. Trop. Anim. Health Prod., v.36, p.537-546, 2004

BAPTISTA, F.; MOREIRA, E.C.; SANTOS, W.L.M.; NAVEDA, L.A.B. Prevalência da tuberculose em bovinos abatidos em Minas Gerais. Arq. Bras. Med. Vet. Zootec., v.56, p.577-580, 2004

BELCHIOR, A.P.C. Prevalência, distribuição regional e fatores de risco da tuberculose bovina em Minas Gerais. 2000. 55f. Dissertação (Mestrado em Medicina Veterinária) - Escola de Veterinária, Universidade Federal de Minas Gerais, Belo Horizonte.

BRASIL. Ministério da Agricultura, Pecuária e Abastecimento. Regulamento Técnico do Programa Nacional de Controle e Erradicação da Brucelose $e$ Tuberculose Animal. Brasília, 2004.

CARDOSO, M.A.; CARDOSO, R.F.; HIRATA, R.D.C. et al. Direct Detection of Mycobacterium bovis in Bovine Lymph Nodes by PCR. Zoonoses Publ. Health, v.56, p.465-470, 2009. 
CORNER, L.A. Post mortem diagnosis of Mycobacterium bovis infection in cattle. Vet. Microbiol., v.40, p.53-63, 1994.

CORNER, L.A.; MELVILLE, L.; McCUBBIN, K. et al. Efficiency of inspection procedures for detection of tuberculous lesions in cattle. Aust. Vet. J., v.67, p.389392, 1990.

FIGUEIREDO, E.E.S.; SILVESTRE, F.G.; CAMPOS, W.N. et al. Identification of Mycobacterium bovis Isolates by a multiplex PCR. Braz. J. Microbiol., v.40, p.231-233, 2009.

FURLANETTO, L.V. Vigilância da tuberculose bovina em abatedouros no estado de Mato Grosso, Brasil. 2011. 122f. Dissertação (Mestrado em Ciência de Alimentos) Instituto de Química, Universidade Federal do Rio de Janeiro, Rio de Janeiro.

FURLANETTO, L.V.; CARVALHO, T.B.; RIBEIRO, G.G.; ZEN, S. Potencial da produtividade e rentabilidade da pecuária de corte do Mato Grosso. In: CONGRESSO DA SOCIEDADE BRASILEIRA DE ECONOMIA ADMINISTRAÇÃO E SOCIOLOGIA RURAL, 48., 2010, Campo Grande. Anais... Campo Grande, 2010. Disponível http://www.sober.org.br/palestra/15/204.pdf. Acessado em: 5 fev. 2011.

INSTITUTO Brasileiro de Geografia e Estatística. Produção da Pecuária Municipal 2007: Bovinos efetivo dos rebanhos. 2007. disponível em: <http://www.ibge.gov.br/cidadesat/topwindow.htm?1>. Acessado em: 17 fev. 2009.

INSTITUTO Brasileiro de Geografia e Estatística. Produção da Pecuária Municipal 2009: Efetivo nacional de bovinos cresce 1,5\% em 2009. 2010. Disponível em: <http://www.ibge.gov.br/home/presidencia/noticias/notici a_impressao. php?id_noticia $=1761>$. Acessado em: 25 fev 2011.

INSTITUTO de Defesa Agropecuária do Estado de Mato Grosso. Caderno de Estatística da Vacinação 2010. Disponível em: http://www.indea.mt.gov.br/html.

KANTOR, I.N.; RITACCO, V. An update on bovine tuberculosis programmes in Latin American and Caribbean countries. Vet. Microbiol., v.112, p.111-118, 2006.

LIEBANA, E.; ARANA, A.; MATEOS, A. et al. Simple and rapid detection of Mycobacterium tuberculosis complex organisms in bovine tissue samples by PCR. $J$. Clin. Microbiol., v.33, p.33-36, 1995.

MARTIN, S.W.; MEEK, A.H.; WILLEBERG, P. Veterinary Epidemiology: Principles and methods. Ames: Iowa State University, 1987. 343p.
MEIKLE, V.; SCHNEIDER, M.; AZENZO, G. et al. Individual animals of a cattle herd infected with the same Mycobacterium bovis genotype shows important variations in bacteriological, histopathological and immune response parameters. Zoonoses Publ. Health., v.54, p.86-93, 2007.

NEGREIROS, R.L.; DIAS, R.A.; FERREIRA, F. et al. Epidemiologia da brucelose bovina no estado de Mato Grosso, Brasil. Arq. Bras. Med. Vet. Zootec., v.61, p.56$65,2009$.

NOORDHUIZEN, J.P.T.M.; FRANKENA, K.; VAN DER HOOFD, C.M.; GRAAF E.A.M. Application of quantitative methods in veterinary epidemiology. Wageningen: Wageningen Pers, 1997. 445p.

REIS, D.O.; ALMEIDA, L.; FARIA, A.R. Estudo comparativo entre linfossarcoma, tuberculose $\mathrm{e}$ linfadenites inespecíficas ocorridas em bovinos abatidos e a confirmação histológica. Hig. Alim., v.35, p.28-30, 1995.

ROXO, E. Situação Atual da Tuberculose Bovina no Brasil.Programa Nacional de Controle e Erradicação de Brucelose e Tuberculose Animal, PNCE bovine tuberculosis. Secretaria de Defesa Agropecuária. Docum. PNCE bovine tuberculosis DDD2005, Sao Paulo, pp. 1-5. 2004.

SALAZAR, F.H.P. Ocorrência de tuberculose causada por Mycobacterium bovis em bovinos abatidos em frigoríficos no estado de Mato Grosso, Brasil. 2005. 73f. Dissertação (Mestrado em Ciência Animal) - Faculdade de Medicina Veterinária e Zootecnia, Universidade Federal de Mato Grosso do Sul, Campo Grande.

SAMPAIO, I.B.M. Estatística Aplicada à Experimentação Animal. Belo Horizonte: FEPMVZ, 1998. 221p.

WARDS, B.J.; COLLINS, D.M.; LISLE, G.W. Detection of Mycobacterium bovis in tissues by polymerase chain reaction. Vet. Microbiol., v.43, p.227-240, 1995.

WHIPPLE, D.L.; BOLIN, C.A.; MILLER, J.M. Distribution of lesions in cattle infected with Mycobacterium bovis. J. Vet. Diagn. Invest., v.8, p.351354, 1996.

ZANINI, M.S.; MOREIRA, E.C.; LOPES, M.T.P. et al. Mycobacterium bovis: polymerase chain reaction identification in bovine lymphonode biopses and genotyping in isolates from Southeast Brazil by spoligotyping and restriction fragment length polymorphism. Mem. Inst. Oswaldo Cruz, v.100, p.749$752,2001$. 